\title{
Simulation of the Pyrolysis Process: from Plastic Waste to Environmental Friendly Fuel
}

\author{
Marius Andersen ${ }^{\mathrm{a}}$, Kai Arne Sætre ${ }^{\mathrm{b}}$, Siw Fredriksen ${ }^{\mathrm{b}}$, Carlos Pfeiffer ${ }^{\mathrm{a}}$ \\ ${ }^{a}$ University College of Southeast Norway, ${ }^{b}$ Norner AS,
}

\author{
mariusandersen87@ outlook.com, \\ carlos.pfeiffer@usn.no
}

kai.saetre@ norner.no,

\author{
Siw.Fredriksen@norner.no,
}

\begin{abstract}
How to deal with plastic waste is an important question, as it may affect both the climate and environment. A method that may be beneficial to dispose some kinds of plastic waste that cannot be material-recycled is thermochemical conversion and, more specifically, pyrolysis. To be able to optimize such a process models are important. This paper describes the results of a study where the main aim was to identify and compare existing published models identifying the important variables regarding the pyrolysis of Polyethylene (PE) and Polypropylene (PP), published in open literature, and to compare these methods with experimental data. Several models were found, of which three were chosen for implementation and further evaluation.

Two of the methods propose the use of lumped kinetic models to predict the product-composition as a function of time and temperature, while the third method uses also the particle size of the polymer as an inputvariable. Comparison with analytical data shows that the models performs well when the assumptions and implications behind them are taken into account.
\end{abstract}

Keywords: Plastic Pyrolysis, Process Simulation, Feedstock Recycling

\section{Introduction}

Since plastics appeared in the 1950s they have changed our world forever. They are cheap to produce, durable and have a wide array of uses. However, if not being recycled properly, plastics can also be a threat to the environment, not to mention a waste of energy and materials (Pinto et al, 1999).

An option proposed, and used to a certain degree, is to recycle plastics is pyrolysis (Beili et al, 2009). This is a process where the material is heated until decomposition in absence of oxygen, yielding a wide array of lighter hydrocarbons.

Experimental results have shown that the final composition of products is highly dependent on the purity and type of polymer(s), temperature and residence time (A. Demirbaş 2005). Optimizing these relationships to give a good tradeoff between cost and product-value is important to make a process profitable, and to do this accurately and robust models are needed.

This paper describes the results of a thesis (Andersen, 2017) where one of the main aims was to find methods to model such a process, to implement and simulate these, and to compare them with experimental data. The experimental data were obtained from reported pyrolysis experiments using virgin HDPE and PP (Azuibuke, 2017).

\subsection{Literature review}

From a literature review several models were found and evaluated for use in the study (Csukas et al, 2013; Ding et al, 2012; Westerhout et al, 1997; Zhang et al, 2015). All the reported models were based on parameters derived experimentally. Pyrolysis is a complex process; thus, these models were based on different kinds of assumptions.

Two simplifications that were often found in the reported models were the assumption of a pure feedmaterial consisting of only one or two polymers, and the neglection of any heat and mass transfer resistance.

The first simplification is invalid if waste-plastic is used, as there will be some food residue, labels and possibly non-desired polymers present.

Studies (Urionabarrenechea, 2011) suggest that different polymers and/or other impurities in the feed may have a strong impact on the reaction mechanism.

Polymers have, in general, a high heat transfer resistance (i.e., thermal conductivity is low). Therefore, it was decided to investigate the validity of the second assumption further. Heat transfer resistance effects may be negligible for small particles, however plastic waste is typically ground only to a suitable size for handling in bulk quantities. and the degree of grinding is a trade-off between cost and benefit.

For the reactions' pathways models, the kinetic parameters used in this article were derived on the assumption of a simple second order Arrheniusmechanism. 


\section{Materials and Methods}

\subsection{Kinetic Models}

The commonly used polyethylene and polypropylene are stable molecules, thus the-overall-reaction breaking them down to smaller products will be an endothermic one. An equation for the reaction for the decomposition rate can be written as follows, assuming an Arrhenius mechanism:

$$
\frac{d X_{P}}{d t}=-X_{p} * A_{0} \cdot e^{-\frac{E a}{R \cdot T}}
$$

where $\mathrm{Xp}$ is the mass fraction of the polymer, $\mathrm{A}_{0}$ is the pre-exponential factor and $\mathrm{Ea}$ is the activation energy for the reaction. It is possible to determine the parameters for the total reaction this by measuring the decomposition rate at different temperatures to provide an Arrhenius-plot.

In order to model the production of valuable fuel components, that is, hydrocarbons with carbon numbers in the range of approx. C4 - C25 a more detailed approach is needed, due to the fuel products decomposing under the same conditions as the polymer. One equation for each of these reactions can be created, but this would be an enormous task due to the sheer number of species, thus reactions, involved.

\subsection{Three Lump model for HDPE and PP/PE mix}

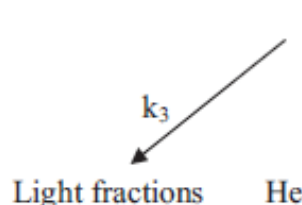

(L) $\longleftarrow \mathrm{k}_{5}$

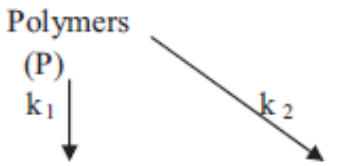

Heavy fractions

(H) Middle distillates

Figure 1 - Proposed reaction pathway by (Ding et al, 2012).

As can be seen in Figure 1 the model proposed by (Ding et al, 2012). is based on the assumption of a reaction pathway consisting of three parallel primary reactions $\left(\mathrm{k}_{1}, \mathrm{k}_{2}, \mathrm{k}_{3}\right)$, and two secondary reactions $\left(\mathrm{k}_{4}\right.$, $\mathrm{k}_{5}$ ), leading to the formation of three product-lumps.

Having defined the different bulks their rates of formation/consumption may be calculated using Equation (2-6) where $\mathrm{X}$ means mass fraction of polymer $(\mathrm{P})$, light $(\mathrm{L})$, medium $(\mathrm{M})$ and heavy $(\mathrm{H})$ product:

$$
\begin{gathered}
\frac{d X_{P}}{d t}=-X_{p} *\left(k_{1}+k_{2}+k_{3}\right) \\
\frac{d X_{H}}{d t}=X_{p} * k_{1}-X_{H} *\left(k_{4}+k_{5}\right) \\
\frac{d X_{M}}{d t}=X_{p} * k_{2}+X_{H} * k_{4}
\end{gathered}
$$

$$
\frac{d X_{L}}{d t}=X_{P} * k_{3}+X_{H} * k_{5}
$$

Where $\mathrm{k}_{1}-\mathrm{k}_{4}$ are expressed as:

$$
k_{i}=A_{0 i} \cdot e^{-\frac{E a_{i}}{R \cdot T}}
$$

Assuming there is only polymer present initially, the initial conditions can be expressed as:

$$
X_{P(0)}=1, X_{H, 0}=X_{M, 0}=X_{L, 0}=0
$$

In order to estimate the Arrhenius parameters, some experimentally-derived rate constants were published in the same article, and an Arrhenius-plot were done on these.

The results of these plots showed a variable degree of linearity. An explanation for this may a reaction order that varies as a function of conversion, as suggested by (Westerhout et al, 1997).

\subsection{Six Step model for Polypropylene}

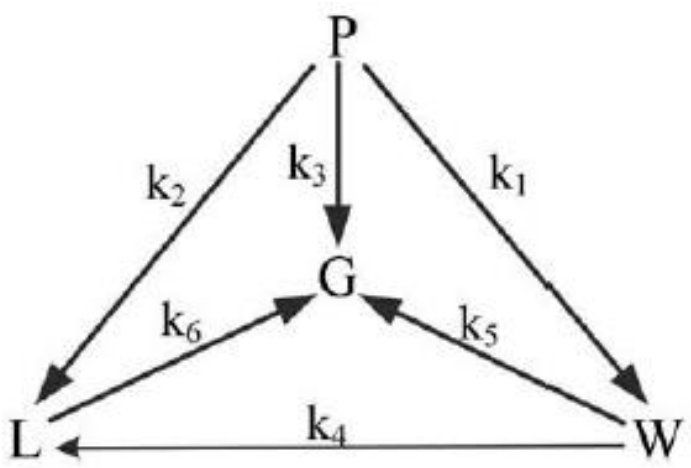

Figure 2 Reaction pathway for PP suggested by (Zhang et al, 2015)

This model, proposed by (Zhang et al, 2015) is based on the assumption of 3 products lumps, gas, liquid and wax, 3 primary reactions $\left(\mathrm{k}_{1}, \mathrm{k}_{2}, \mathrm{k}_{3}\right)$ and 3 secondary reactions $\left(\mathrm{k}_{4}, \mathrm{k}_{5}, \mathrm{k}_{6}\right)$.

This reaction pathway thus gives the following set of equations where $\mathrm{X}$ denotes mass fraction of the polymer $(\mathrm{P})$, liquid $(\mathrm{L})$, wax $(\mathrm{W})$ and gas $(\mathrm{G})$ :

$$
\frac{\mathrm{dX}}{\mathrm{dt}}=-\mathrm{X}_{\mathrm{p}} *\left(\mathrm{k}_{1}+\mathrm{k}_{2}+\mathrm{k}_{3}\right)
$$

$$
\begin{aligned}
& \frac{d X_{L}}{d t}=X_{p} * k_{2}+X_{W} * k_{4}-X_{L} * k_{6} \\
& \frac{d X_{\mathrm{W}}}{\mathrm{dt}}=\mathrm{X}_{\mathrm{p}} * \mathrm{k}_{1}-\mathrm{X}_{\mathrm{W}} *\left(\mathrm{k}_{5}+\mathrm{k}_{6}\right) \\
& \frac{\mathrm{dX} \mathrm{G}}{\mathrm{dt}}=\mathrm{X}_{\mathrm{p}} * \mathrm{k}_{3}+\mathrm{X}_{\mathrm{L}} * \mathrm{k}_{6}+\mathrm{X}_{\mathrm{L}} * \mathrm{k}_{5}
\end{aligned}
$$




\subsection{Heat transfer model}

The third model implemented in this study is a heat transfer model (Westerhout et al, 1997). The model is based on an energy balance of a single particle, as can be seen below.

$$
\rho_{p} c_{p p} \frac{\partial T_{p}}{\partial t}=k_{p} \frac{1}{x^{\gamma}} \frac{\partial\left(x^{\gamma} \frac{\partial T_{p}}{\partial x}\right)}{\partial x}-\frac{\partial \xi}{\partial t} \rho_{p 0} \Delta H_{r}
$$

Where the meaning of the symbols is explained in Table 1:

\section{Table 1 Explanation of symbols used in model}

\begin{tabular}{|c|l|}
\hline Symbol & Description [Unit] \\
\hline$\rho_{p}$ & Density of the particle $\left[\mathrm{kg} / \mathrm{m}^{3}\right]$ \\
\hline$\rho_{p 0}$ & Density at $\mathrm{t}=0\left[\mathrm{~kg} / \mathrm{m}^{3}\right]$ \\
\hline$x$ & Radial coordinate of the particle $[\mathrm{m}]$ \\
\hline$\xi$ & Conversion [-] \\
\hline$\gamma$ & Geometric factor [-] \\
\hline$H_{r}$ & Heat of reaction $[\mathrm{J} / \mathrm{kg}]$ \\
\hline$c_{p p}$ & Heat capacity $[\mathrm{J} / \mathrm{kg} \mathrm{K}]$ \\
\hline$k_{p}$ & Conductive transfer coefficient $\left[\mathrm{W} / \mathrm{m}^{2} \mathrm{~K}\right]$ \\
\hline$T_{p}$ & Temperature of particle $[\mathrm{K}]$ \\
\hline$T_{S}$ & Temperature of surroundings $[\mathrm{K}]$ \\
\hline$h$ & Convective transfer coefficient $\left[\mathrm{W} / \mathrm{m}^{2} \mathrm{~K}\right]$ \\
\hline$\epsilon$ & Emissivity $[\mathrm{W} / \mathrm{m} 2 \mathrm{~K} 4]$ \\
\hline
\end{tabular}

Assuming the volume to be constant $x^{\gamma}$, and only the density decreasing as the reactions occur within the particle, e.g. particle getting more porous as the reaction takes place thorough the constant volume, the $x^{\gamma}$ can be taken out of the derivative and canceled against $1 / x^{\gamma}$.

To simplify:

$$
\frac{k_{p}}{\rho_{p} c_{p p}}=\mathrm{r}
$$

And

$$
\rho_{p}=\rho_{0}(1-\xi)
$$

Assuming Arrhenius kinetics, the mass balance can then be formulated as:

$$
\frac{\partial \xi}{\partial t}=A_{0} * e^{\frac{-E a}{R T_{p}}} *(1-\xi)
$$

With the following boundary and initial conditions:

$$
\mathrm{t}=0 \forall x=T_{p}=T_{0} \cap \xi=0
$$

$$
\begin{aligned}
& x=0 \forall t \frac{\partial T_{p}}{\partial x}=0 \\
& x=r_{p} \forall t \frac{\partial T_{p}}{\partial x}=\frac{h}{k_{p}}\left(T_{s}-T_{p, x=x p}\right) \\
& +\epsilon \sigma\left(T_{s}^{4}-T_{p, x=x p}{ }^{4}\right)
\end{aligned}
$$

After combining, the equation is then discretized in time and space:

$$
\begin{aligned}
T_{p, n}^{i+1}=b T_{n+1}^{i}- & \left.(1-2 b) T_{p, n}^{i}+b T_{p, n-1}^{i}\right) \\
& -\frac{\rho_{p 0} r \Delta H_{r}}{k_{p}}\left(A_{0} * e^{\frac{-E a}{T_{p, n}^{i}}} *(1\right. \\
& \left.\left.-\xi^{i}\right)\right)
\end{aligned}
$$

The initial condition is

$\mathrm{T}(0, \mathrm{x})=\mathrm{T}_{0}$

The Neumann boundary conditions are:

$$
\begin{aligned}
& \mathrm{x}=\mathrm{r}_{\mathrm{p}} \forall \mathrm{t} \frac{\partial \mathrm{T}_{\mathrm{p}}}{\partial \mathrm{x}}=\frac{\mathrm{h}}{\mathrm{k}_{\mathrm{p}}}\left(\mathrm{T}_{\mathrm{s}}-\mathrm{T}_{\mathrm{p}, \mathrm{x}=\mathrm{xp}}\right) \\
& +\epsilon \sigma\left(\mathrm{T}_{\mathrm{s}}{ }^{4}-\mathrm{T}_{\mathrm{p}, \mathrm{x}=\mathrm{xp}}{ }^{4}\right) \\
& \mathrm{T}_{\mathrm{n}+1}^{\mathrm{i}}=-2 \Delta \mathrm{x} \frac{\mathrm{h}}{\mathrm{k}_{\mathrm{p}}}\left(\mathrm{T}_{\mathrm{s}}-\mathrm{T}_{\mathrm{p}, \mathrm{n}}^{\mathrm{i}}\right) \\
& +\epsilon \sigma\left(\mathrm{T}_{\mathrm{s}}{ }^{4}-\mathrm{T}_{\mathrm{p}, \mathrm{n}}{ }^{4}\right)+\mathrm{T}_{\mathrm{n}-1}^{\mathrm{i}}
\end{aligned}
$$

\section{Results and Discussions}

\subsection{Kinetic Models}

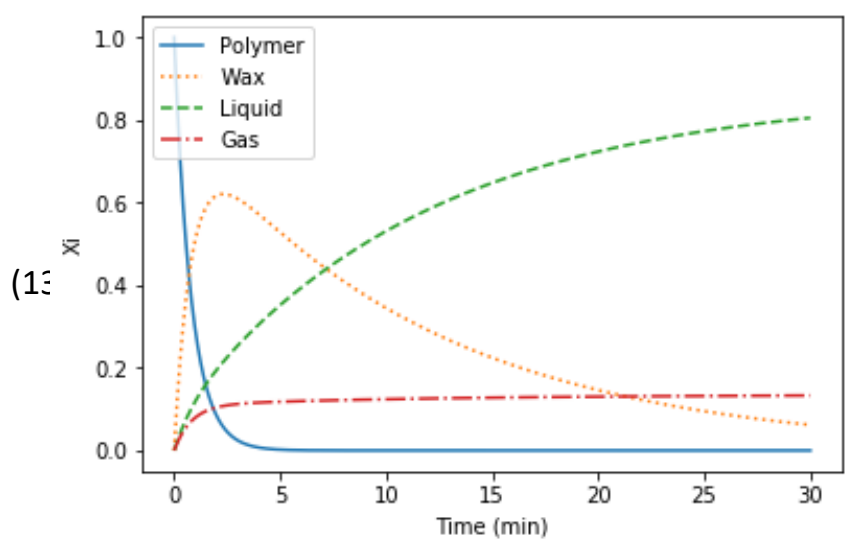

Figure 3 - Results of kinetic models for PP at $400 \mathrm{C}$.

As can be seen in Figure 3 the model gives results in the range of what can be expected from pyrolysis at these temperatures. These plots, being a function of both the primary and secondary reactions is difficult to validate without suitable experimental data tailored to fit the model. This is especially due to the fact that two 
similar phases at high temperatures are present (wax and liquid), and because the exact composition and physical properties were poorly defined in the literature where the kinetic data was sourced from.

In order to validate the model, TGA (ThermoGravimetric Analysis) data were used. The data was sourced from the thesis of (A. Azuibuke, 2017). Thermogravimetric analysis works by measuring the mass of a sample while the temperature is ramped.

Hence, if the rate of decomposition of the polymer can be validated against the TGA-data, this should at least validate that the total magnitude of the primary reactions is correct.

Part of the difference between the model predicted TGA and the experimental results, can be attributed to the difference in conditions in a TGA meter and a pyrolysis reactor/autoclave which the kinetic data has been sourced from.

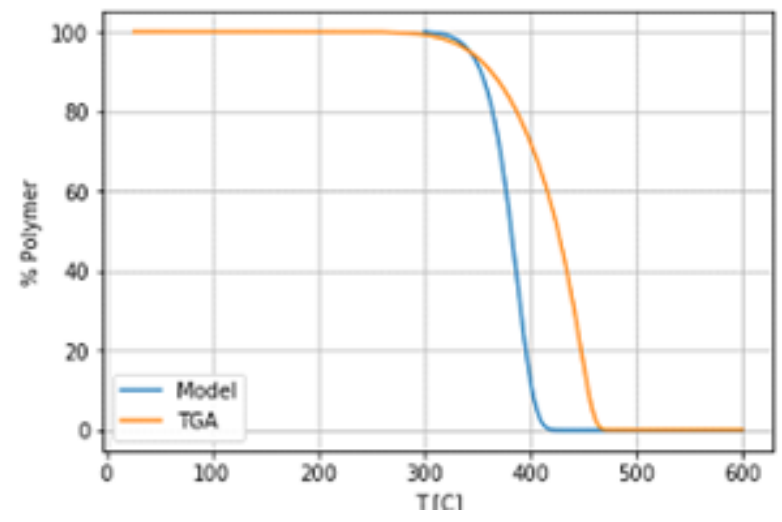

Figure 4 - Comparison between PP model and TGA. $10{ }^{\circ} \mathrm{C} / \mathrm{min}$ rate.

The comparison of experimentally obtained TGAdata with the TGA modeling results from the 3-step model for PP are shown in Figure 6

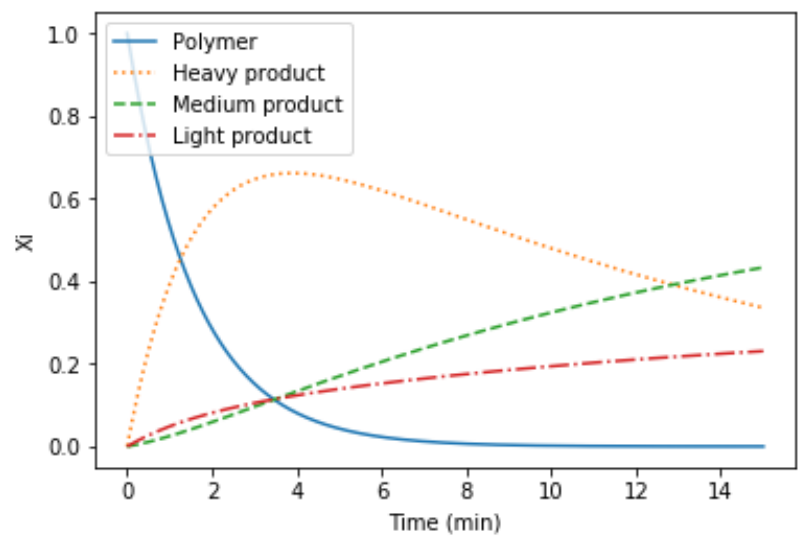

C.

Figure 5 - Results of kinetic models for HDPE at 450

Results of the HDPE-model can be seen in Figure 5. As can be seen, it decomposes somewhat slower, even though the temperature is higher than for the PPsimulation. This is can be explained due to PP having a more branched structure than PE, making it more prone to breaking apart.

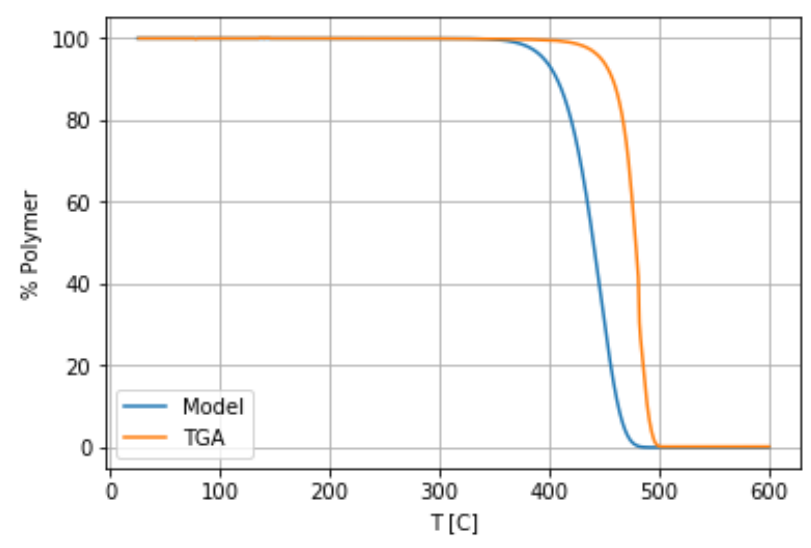

Figure 6 - Comparison between HDPE model and TGA. $10^{\circ} \mathrm{C} / \mathrm{min}$ rate.

The HDPE-model was also validated against TGA-data sourced from (A. Azuibuke, 2017). As can be seen in Figure 6 it shows a similar magnitude of accuracy as the PP-model

\subsection{Thermal model}

As with the pure kinetic model the thermal model were also compared with TGA-data from (A. Azuibuke, 2017). The polymer pellets were almost spherical and the average diameter $(1-3 \mathrm{~mm})$ as used as a parameter in the model. In Figure 7 the results of a comparison between the model and TGA results can be seen for HDPE.

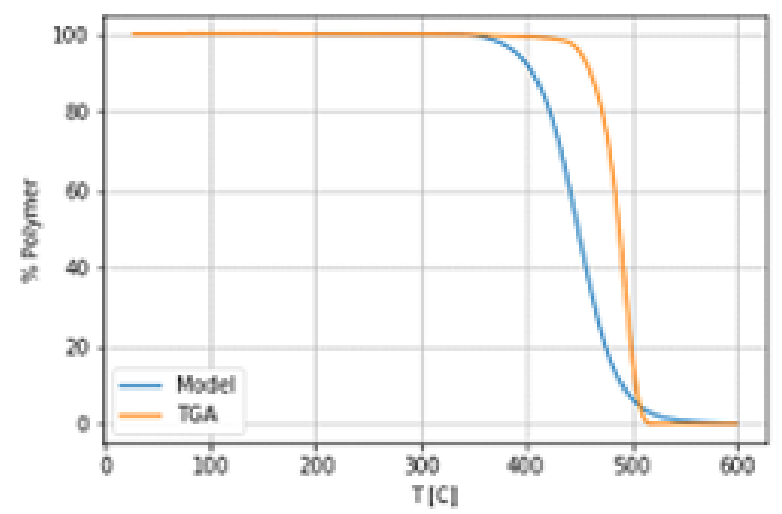

Figure 7 - Comparison between HDPE model and TGA. $10^{\circ} \mathrm{C} / \mathrm{min}$ rate. 


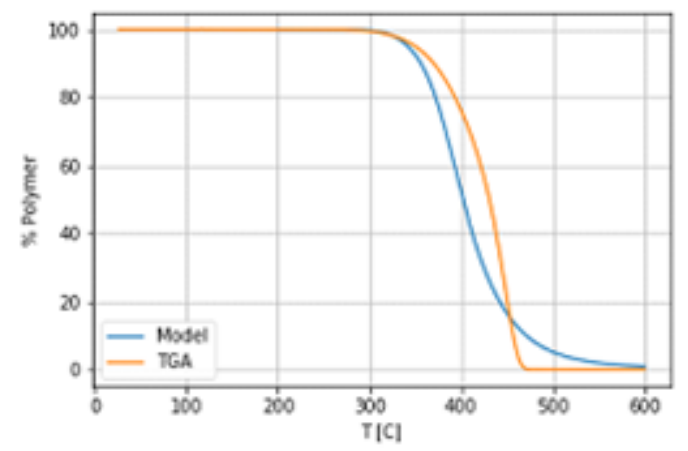

Figure 8 - Comparison between PP model 1 and TGA. $10^{\circ} \mathrm{C} / \mathrm{min}$ rate.

In Figure 8 the results of the comparison of between the model and TGA-results can be seen for PP. Since both the pure kinetic model and this model is using the same kinetic parameters this implies that it is important to take heat transfer resistance in to account when modeling polymer pyrolysis. It is probably also possible that heat transfer resistance will affect the composition of the products as many of the species will be prone to decompose by means of the same kind of mechanisms as the polymer itself.

In Table 2 the $\%$ deviation between the thermal models and the TGA-results can be seen.

Table 2 - $\%$ Deviation of $90 \%$ conversion temperature between models and TGA for two heating rates.

\begin{tabular}{|l|r|r|}
\hline $\begin{array}{l}{\left[{ }^{\circ} \mathrm{C} / \mathrm{min}\right]} \\
\text { Polymer }\end{array}$ & 10 & \\
\hline PP - Model & 1.74 & 6.20 \\
\hline HDPE - Model & 2.37 & 6.64 \\
\hline
\end{tabular}

\section{Conclusions}

It can be concluded that the decomposition of pure polymers by pyrolysis can be modeled with a good ( 90-95\%) accuracy using models can be found in open literature. With larger particles $(1 \mathrm{~mm}+)$ and/or high temperature it is also important to model heat transfer resistance to get accurate results. If more accurate results are sought more complex models will be needed to account for factors such as variable reaction order, feed composition and structure, and in general the complexity of the multiple radical type of reactions that makes up the pathway between reactant and product.

The models presented in this report could be used together with the energy balance, operation cost estimations and products values, to find the optimal residence time that maximizes the profit for the pyrolysis process. However, to estimate this further work is recommended as the product fractions would probably have to be more precisely defined in terms of fuel-value, and the models' robustness towards nonidealities such as impurities commonly found in plastic waste should be evaluated.

\section{Bibliographic References}

M. Andersen, Process simulation of plastic waste to environmental friendly fuel, Master Thesis, University College of Southeast Norway, 2017

A. Azubuike, Experimental study of catalysis in plastic pyrolysis, Master Thesis, University College of Southeast Norway, 2017.

W. Beili, M. Fukushima, K. Wakai, H. Ibe, S. Ito "Current issues of oil reclamation system for recycling municipal waste plastic containing PVC and PET in Japan." The 5th symposium on feedstock and mechanical recycling of polymeric materials (ISFR2009). 2009.

B. Csukas, M. Varga, N. Miskolczi, S. Balogh, A. Angyal, and L. Bartha, "Simplified dynamic simulation model of plastic waste pyrolysis in laboratory and pilot scale tubular reactor," Fuel processing technology, vol. 106, pp. 186-200, 2013.

A. Demirbaş, "Recovery of Chemicals and Gasoline-Range Fuels from Plastic Wastes via Pyrolysis", Energy Sources 27:14, pp. 1313-1319, 2005.

F. Ding, L. Xiong, C. Luo, H. Zhang, and X. Chen, "Kinetic study of low-temperature conversion of plastic mixtures to value added products," Journal of Analytical and Applied Pyrolysis, vol. 94, pp. 83-90, 2012.

F. Pinto, P. Costa, I. Gulyurtlu, I Cabrita "Pyrolysis of plastic wastes. 1. Effect of plastic waste composition on product yield", Journal of Analytical and Applied Pyrolysis, vol 51, pp. 39-55, 1999.

A. Urionabarrenechea, "Chemical recycling of municipal packaging waste by pyrolysis," Phd, University of the Basque Country, 2011.

R. Westerhout, R. Balk, R. Meijer, J. Kuipers, and W. Van Swaaij, "Examination and evaluation of the use of screen heaters for the measurement of the high temperature pyrolysis kinetics of polyethene and polypropene," Industrial \& engineering chemistry research, vol. 36, pp. 3360-3368, 1997.

R. Westerhout, J. Waanders, J. Kuipers, and W. Van Swaaij, "Kinetics of the low-temperature pyrolysis of polyethene, polypropene, and polystyrene modeling, experimental determination, and comparison with literature models and data," Industrial \& Engineering Chemistry Research, vol. 36, pp. 1955-1964, 1997.

H. Zhang, F. Ding, C. Luo, and X. Chen, "Kinetics of the Low Temperature Conversion of Polypropylene to Polypropylene Wax," Energy Sources, Part A: Recovery, Utilization, and Environmental Effects, vol. 37, pp. 16121619, 2015. 